\title{
Production of Low Emission Pellet from Coco Peat Waste
}

\author{
Rizal Alamsyah $^{1}$ and Nobel Christian Siregar ${ }^{2}$
}

\begin{abstract}
Study was conducted on coco peat as a low emission pellet form biomass fuel alternative to produce synthetic gas (syngas) through gasification process in use for other processes. Coco peat was first screened and formulated with other materials such as coco peat, starch, and waste cooking oil. These materials were mixed and pelletized using a pelletizer to form coco peat pellet. It was burned on an updraft gasifier to produce synthetic gas (syngas) and then streamed to a stove through a pipe. The syngas was then split and burned and the heat generated was used for boiling water and for drying agricultural products. Air quality around the stove (emission test) was measured and analyzed when gasification took place. The best results of coco peat pellet were made from $85 \%$ of coco peat waste, $5 \%$ starch (binder), and $10 \%$ of waste cooking oil with stronger texture and shiny surface. The experimental gasification using updraft gasifier exhibited better result when half of the volume of gasifier was filled with $5 \mathrm{~kg}$ pellet and the syngas produced can be used for 3.5 hours drying and boiling. Air quality surrounding the stove was tested during gasification process. It was done based on the Indonesian Environmental Regulation issued by Indonesian the Ministry of Environment on Standards (KEP-13/MENLH/3/1995 dated March $7^{\text {th }}$, 1995) regarding standard air quality from static matter and covers $\mathrm{NH}_{3}, \mathrm{Cl}_{2}, \mathrm{HCl}, \mathrm{HF}, \mathrm{NO}_{2}$, particles, $\mathrm{SO}_{2}$ and $\mathrm{H}_{2} \mathrm{~S}$ parameters. The result of measurements indicated that all parameters meet the quality standards) including $\mathrm{CO}$ and $\mathrm{CO}_{2}$ at $0.0001 \mathrm{mg} / \mathrm{kg}$.
\end{abstract}

Keywords: coco peat, biomass, low emission, gasification, pellet, synthetic gas (syngas).

\footnotetext{
${ }^{1}$ Center for Agro-Based Industry (CABI), Jl. Ir. Juanda No.11, Bogor, 16122 Jawa Barat, Indonesia.

Email: rizalams@yahoo.com

${ }^{2}$ Center for Agro-Based Industry (CABI), Ministry of Industry, Indonesia.
} 


\section{Introduction}

The rapid depletion of oil reserve will force many countries including Indonesia to find alternative energy supply to sustain economic development (Dasuki, 2000; Abdullah, 2007). One of the alternative energy supplies or resources is biomass especially coming from agricultural waste products which is abundant in Indonesia. Biomass resources can be transformed into different kinds of energy. Solid biomass is commonly used as fuel for cooking and other thermal processes in small and medium industries, as fuel for boilers, but can also be transformed into gaseous and liquid fuel such as ethanol and bio-diesel (Carraretto, et al., 2004). To accelerate the utilization of renewable energy in Indonesia, the government has issued a draft of new energy policy in order to promote further development of renewable energy sources, improve energy efficiency and greenhouse gas (GHG) abatement called the "green energy insight" (Salim, 2000; Ariyati, 2007). In addition, agricultural wastes or fire woods are still the main source of energy for cooking in most of the developing countries including Indonesia, besides kerosene and gas (Abdullah, 2007).

Coconut production plays an important role in the national economy of the Indonesia. Indonesia is one of the second largest coconut producing countries among the APCC (AsianPacific Coconut Community) member countries, after The Philippines. The average production of coconut of Indonesia is 16.8 billion nuts/year or equivalent to3.29 million tons copra,4.08 million tons coconut water, 0.80 million tons coconut shell charcoal, 1.96 million tons husk, and 3.59 million tons coco peat (Directorate General of Estate Crops, Ministry of Agriculture, 2011). This figure seemingly will increase in the near future, due to various national projects such as the establishment of a coconut nucleus estate and hybridization (Romulo, 2009).

The utilization of coconut in Indonesia is mainly for coconut oil, coconut milk or cream, cooking oil, desiccated coconut, soft drink, bacterial-cellulose, young dried coconut meat, pasteurized coconut milk, sterilized coconut milk, nata de coco, coco-vinegar, charcoal, copra, activated carbon, coconut fiber, virgin coconut oil and coconut wood (Allorerung, 1998; Mahmud and Ferry, 2005; APCC, 2012). These products have been exported with excellent progress except for coconut fiber due to standards. So far coconut based oleo chemicals (OC) have not been produced and to fulfill the domestic needs, the products are imported from other countries. Coco peat is produced as a by-product from fiber processing. Actually there are many parties that need coco peat for further processing, but because of the long distance and transportation cost, coco peat has not been fully utilized.

Based on mass balance, the amount of coco peat to fiber ratio is 1: 10 (Alamsyah et al., 2011). In Indonesia, the utilization of coco peat is still limited for media of plant growing; therefore coco peat is dumped as a solid waste (Kristijono, 2010). Actually coco peat could be used as a raw material for renewable energy sources. This could be seen in the analysis of raw material which shows that it has: 16640 $\mathrm{kJ} / \mathrm{kg}$ calorific value; $22.05 \%$ fixed carbon, $6.14 \%$ ash, $71.80 \%$ volatile matter, $14.20 \%$ moisture, and $1.14 \%$ silica (Alamsyah et al., 2011). Coco peat could be processed as a biomass pellet for solid fuel (Belonio, 2012). There is a need to identify and create the coconut products apart from traditionally produced and exported coconut product that have more added value and which will generate more income in the existing market and in the non-traditional markets (Romulo, 2012).

To support industrialization through the development of agro-based industries, all agricultural product including biomass waste or by-products should be treated as raw materials for other products or renewable energy sources. To maximize the utilization of coconut, some efforts should be conducted to develop coconut processing industries involving by-products and utilizing coco peat for heat generation. Coco peat as feed stock can be processed into pellet shape and when they are burned using gasifiers, it will produce synthetic gas $\left(\mathrm{H}_{2}\right.$ and others) that can be used as energy/heat source for cooking in households and drying for agricultural products. 
This paper was aimed to formulate coco peat biomass to form coco peat pellet, to test the quality of pellet, to produce synthetic gas (syngas) through gasification process, and to test gas emission resulted from stove using synthetic gas produced. It is hoped that the information will be useful for those who have the problem in reducing or reusing coco peat as solid waste especially for the APCC member countries.

\section{Materials and methods}

\section{Materials}

Materials used for making pellets consist of coco peat, tapioca starch, and waste cooking oil. Coco peat was obtained from Serang, Banten Province, Indonesia with moisture content of $20 \%$, energy content of $16640 \mathrm{~kJ} / \mathrm{kg}$, and density of $0.12 \mathrm{~kg} / \mathrm{l}$. Tapioca starch, which was used as binding agent, was obtained from a local store. Waste cooking oil was used for improving rheological properties of pellet especially during pelletizing.

Equipment

1. Biomass pelletizer- capacity of 100 $\mathrm{kg}$ /hour and a power of $10 \mathrm{HP}$; pellet form with $3 \mathrm{~cm}$ length and $8 \mathrm{~mm}$ diameter

2. Updraft gasifier - $60 \times 48 \mathrm{~cm}$; maximum holding capacity $10 \mathrm{~kg}$

3. Emission tester - Indonesian Environmental Regulation issued by Indonesian Ministry of Environmental Affairs (KEP-13/MENLH/3/1995 dated March $7^{\text {th }}$ ，1995) regarding air quality standards from static matter which covers $\mathrm{NH}_{3}, \mathrm{Cl}_{2}, \mathrm{HCl}, \mathrm{HF}, \mathrm{NO}_{2}$, particle, $\mathrm{SO}_{2}$ and $\mathrm{H}_{2} \mathrm{~S}$ parameters

Auxiliary equipment

1. Sieve (60 mesh) for sifting coco peat

2. Plastic bag - $20 \mathrm{~kg}$ holding capacity for packing pellets after cooling to avoid moisture gain

3. Beaker glass $-2 \mathrm{~L}$ maximum capacity for measuring liquid smoke production

\section{Methods}

The process of producing fuel pellets involves some unit operations, namely sorting, sifting, drying, weighing, mixing, pelletizing, cooling, packing, gasification, and emission test. The description of each step or unit operation is described as follows (Figure 1).

\section{Energy and proximate analysis}

Before conducting pelletization and gasification ofcoco peat pelletsinto syngas, materials for pellet formulationwere tested in terms of calorific (energy) and proximate analysis. The parameter of proximate analysis consists of moisture, silicate, fiber, and dry matter content.

\section{Sorting and sifting}

Sortation of raw materials was required since coco peat must be uniform in size prior to making good quality of the pellet shape and structure, and improving the density of pellets produced. This is usually conducted using a sieve (60 mesh). In addition, this unit operation was used for separating foreign materials such as metal or stones from the feedstock.Size reduction was also conducted to get small size of biomass pellet in order to make uniform materials and to make solid form of pellets (Mani, Tabil, and Sokhansanj, 2003; Nielsen et al., 2009).

\section{Drying and weighing}

Moisture was removed from the feedstock by oven-drying at temperature of $50^{\circ} \mathrm{C}$. If the feedstock is too dry, moisture can be added by injecting steam or water into the feed stock. Coco peat typically has around $20 \%$ wet basis (wb) and must be dried prior to processing. Drying of raw materials was conducted to reach uniform drying level (14\% wb) in order to have good pellet structure and to produce low emission pellet. When moisture content is higher than $14 \%$, then the pellet will release smoke and create environmental pollution. Maintaining an appropriate moisture level in coco peat is vital for overall quality of the final pellets. 
Cord 2013, 29 (2)

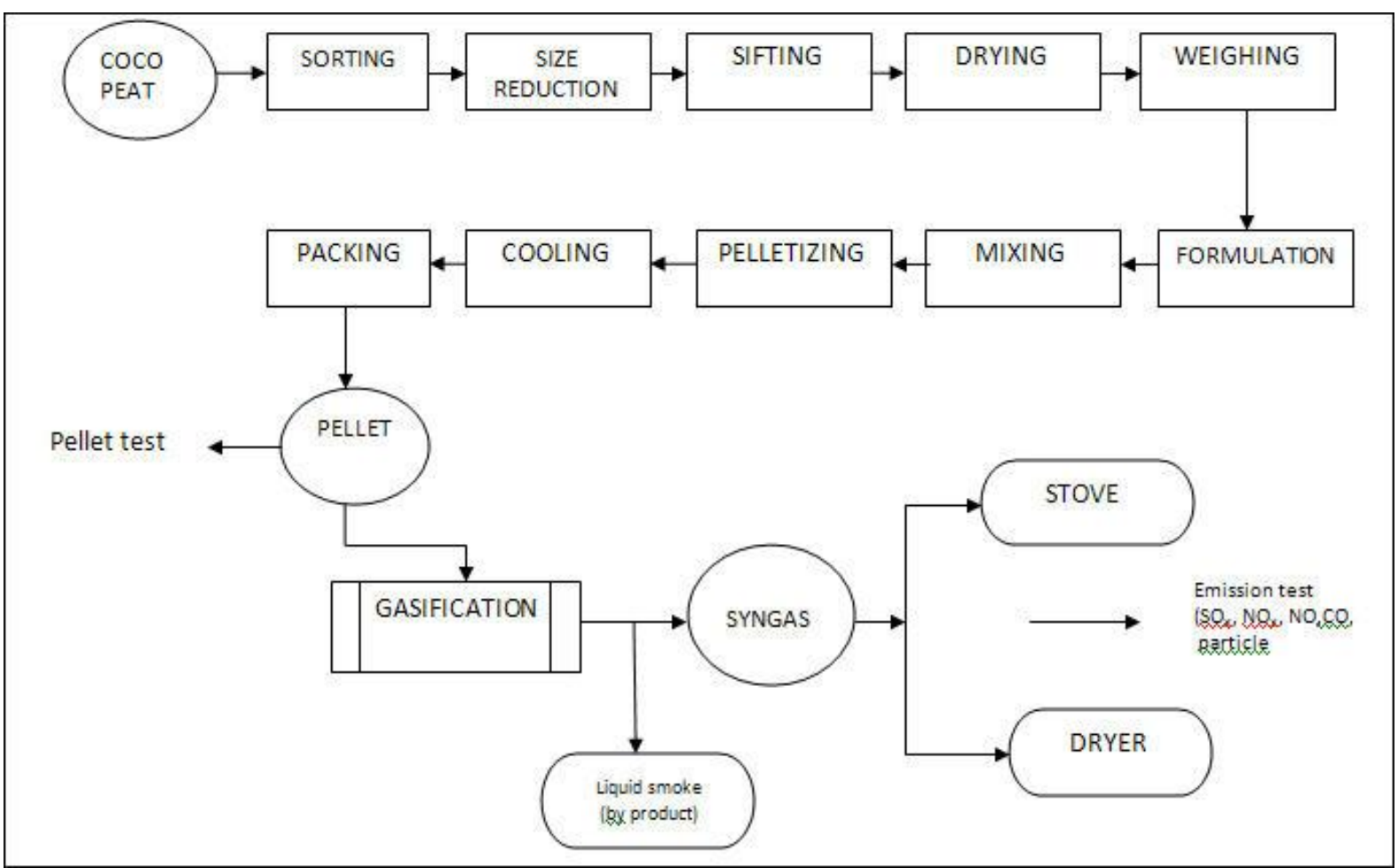

Figure 1. Flow process of coco peat production and test

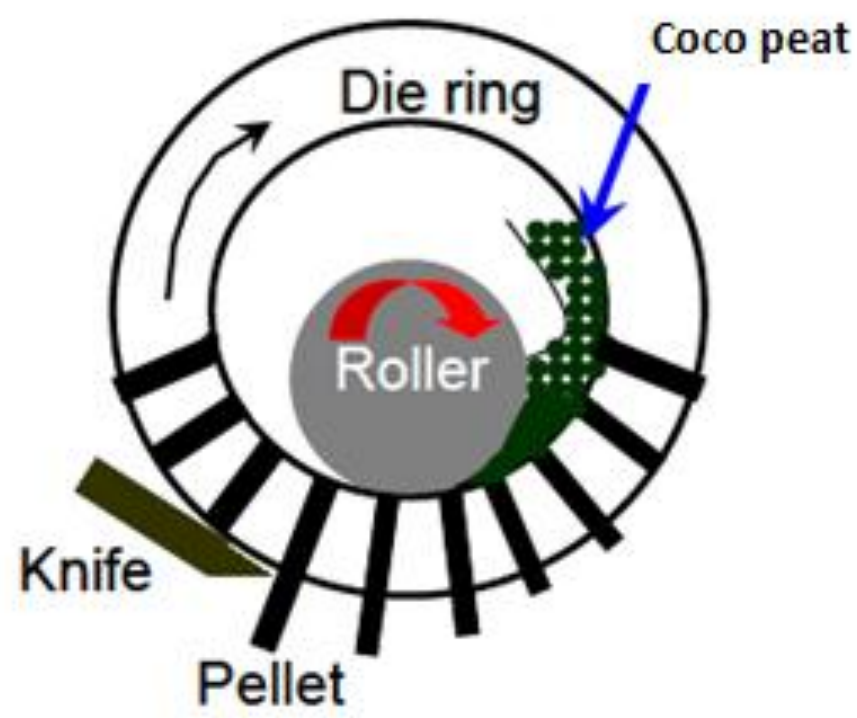

Figure 2. Mechanism of coco peat pelletizing 


\section{Formulating and mixing}

Formulation is one of the critical processes of quantifying the amount of pellet materials that need to be put together to form a single uniform mixture of pellets that would supply all of energy release. Feed formulation is also a key operation in pellet production, ensuring that pellet ingredients are economically used for syngas production. It is therefore essential that formulations are accurate to ensure that a large number of flocks are not adversely affected. For this study, two formulas were designed: Formula I and Formula II. The Formula I was composed of $85 \%$ coco peat, $5 \%$ tapioca starch, and $10 \%$ waste cooking oil while Formula II was composed of $90 \%$ coco peat, $5 \%$ starch, and 5\% waste cooking oil. Tapioca starch was used as binding agent to improve the structure of pellet meanwhile waste cooking oil was applied to improve rheological properties of pellet materials when pelleting (Pfost and Young, 1974).

Mixing was done using a mixer to homogenize all raw materials. Mixing is also one of the important step that should be done since raw materials have to be homogenized in order to have homogeneous energy content of the pellets when gasification takes place (Perry and Green, 1999).

\section{Pelletizing}

Pelletizing process was done by using a pelletizer unit with capacity of $100 \mathrm{~kg} / \mathrm{hour}$ and a power of $10 \mathrm{HP}$. Pelletizing is intended to form biomass waste in pellet form with $3 \mathrm{~cm}$ in length and $8 \mathrm{~mm}$ in diameter. A roller is used to compress the biomass against a heated metal plate called die. The die includes several small holes drilled through it, which allow the coco peat to be squeezed through under high temperature and pressure conditions (Robinson, 1984). If the conditions are right, the biomass particles will compress into a solid mass, thus turning into a pellet. A knife is typically used to cut the pellet to a predefined length as it exits the die. The mechanism of pelletizing was presented in Figure 2.

\section{Cooling and packing}

Cooling pellets as they leave the die was done by blowing air from an axial fan. The pellet should be cooled soon since the pellets are covered by water which come from internal part of pellet when pressed. The pellets leaving the die are quite hot and fairly soft. Therefore, they must be cooled and dried before they are used. This is usually achieved by blowing air through the pellets as they sit in a metal bin. As pellets get cooled, they should be immediately packed otherwise it could absorb moisture from the surrounding. Pellets were then packed in a plastic bag with a capacity of $20 \mathrm{~kg}$.

\section{Gasification}

Gasification process was conducted using an updraft gasifier presented in Figure 3. The height and diameter of gasifier are $60 \mathrm{~cm}$ and 48 $\mathrm{cm}$, respectively. The capacity of feed gasification was $10 \mathrm{~kg}$ coco peat pellet. Gasification can be explained as a staged combustion process andthis can be done by burning coco peat pelletat a limited supply of oxygen. The gas which is produced from combustion still has potential to be burned. The objective of gasification is to break complex molecule bonds into simple gases i.e.hydrogen gas $\left(\mathrm{H}_{2}\right)$ and carbon monoxide $(\mathrm{CO}) . \mathrm{H}_{2}$ gas as a main component of a syngas has very clean burning characteristics a high flame propagation speed and wide flammability limits (Azimov et al., 2012).

During its operation, coco peat pellet was fed from the top (6) and burned in the gasification chamber (5) while fresh air was flowed using fan (1) through fresh air inlet (2) where the flow rate of fresh air was controlled with a valve (3). On the gasifier, the air reacts with cocopeat producing synthetic gas $\left(\mathrm{H}_{2}\right.$ and $\mathrm{CO})$. The synthetic gas produced was flowed through syngas outlet (7) and it was controlled with syngas valve (8). The synthetic gas was split into two pipes and was ignited for drying agricultural products (10) and for boiling water (11). During synthetic gas production, coco peat vinegar or liquid smoke was generated as a byproduct and it was measured using a beaker glass (12). 


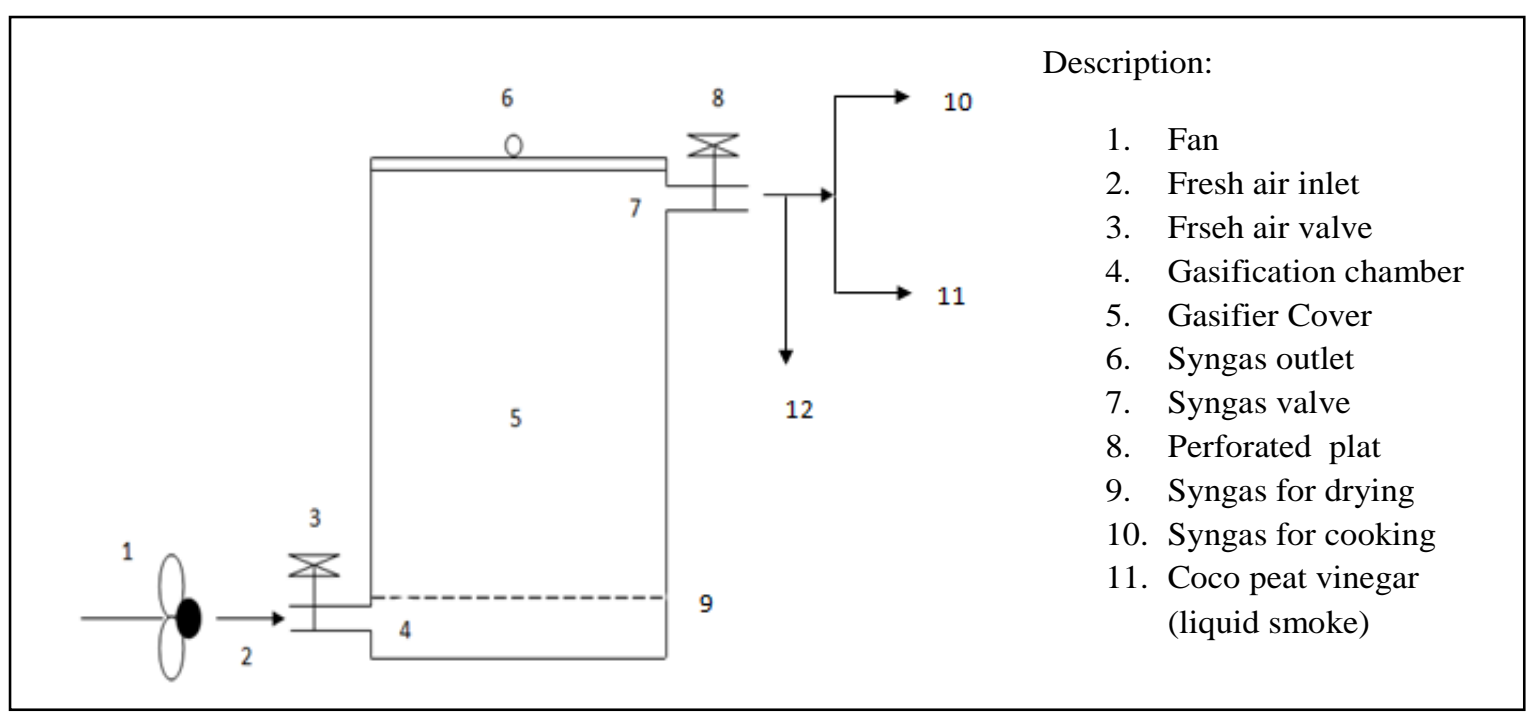

Figure 3. Coco peat gasification with updraft gasifier

\section{Emission test}

The purpose of the emission test is to measure emissions from pellet fuel as required by air quality standard set up by Decree of the Minister of Environment on Standards of Quality Stationary Source Emissions No: KEP13/MENLH/3/1995 dated March $7^{\text {th }}, 1995$. Ultimately, the goal is to ensure that such pellets can be commercialized and comply with available emission standards.

Quality pellets are essential to ensure clean combustion.To evaluate emission of combustion process, emission test was conducted. The emission test result which consists of $\mathrm{NH}_{3}, \mathrm{Cl}_{2}$, $\mathrm{HCl}, \mathrm{HF}, \mathrm{NO}_{2}$, particle, $\mathrm{SO}_{2}$, and $\mathrm{H}_{2} \mathrm{~S}$ is shown on Table 3. Based of this table, it was concluded that emission generated from combustion ofbiomass pellet meets the requirement of Air Quality Standards established by Decree of the Minister of Environment on Standards of Quality Stationary Source Emissions No: KEP13/MENLH/3/1995 on March7 ${ }^{\text {th }}, 1995$

The experiment of gasification and emission testing were conducted on all pellets produced. Emission tests are performed based on the Indonesian Environmental Regulation with the purpose of determining compliance with air pollution permits and regulations issued by Indonesian Ministry of Environmental Affairs.
All emission testing must be conducted in accordance to procedures prescribed by or acceptable to the Indonesian Environmental Regulation issued by Indonesian Ministry of Environmental Affairs (KEP-13/MENLH/3/1995 dated March $7^{\text {th }}$, 1995) regarding air quality standards from static matter which covers $\mathrm{NH}_{3}$, $\mathrm{Cl}_{2}, \mathrm{HCl}, \mathrm{HF}, \mathrm{NO}_{2}$, particle, $\mathrm{SO}_{2}$ and $\mathrm{H}_{2} \mathrm{~S}$ parameters. These guidelines are designed to ensure standardization of test requirements, standards regarding test equipment and competence of persons who perform emission tests. Failure to follow these guidelines or provide the information required may result in the rejection of the test and/or test program.

\section{Results and discussion}

\section{Pellet Quality}

The test results for coco peat quality from the experiments is presented in Table 1. The coco peat pellet and liquid smoke or coco peat vinegar were presented in Figure 4. For evaluating the quality of pellet, its characteristics such as size texture, surface condition, length, density, diameter, ash content, moisture content, and calorific value should be examined. For this preliminary research, the test results for coco peat pellet as solid fuel for gasification was compared with the other standards. Since there is no specification or standard for coco peat pellet, 
Table 1. The test results for cocopeat as solid fuel compared to DIN Standard and others

\begin{tabular}{|c|c|c|c|c|c|c|}
\hline \multirow[t]{2}{*}{ Parameter } & \multirow[t]{2}{*}{ unit } & \multicolumn{2}{|c|}{ Cocopeat pellet } & \multirow{2}{*}{$\begin{array}{c}\text { DIN } 51731 \\
\text { Standard }\end{array}$} & \multirow[t]{2}{*}{ ENplus-A1* } & \multirow[t]{2}{*}{ EN-B* } \\
\hline & & Formula I & Formula II & & & \\
\hline Texture & - & strong & fragile & strong & strong & strong \\
\hline $\begin{array}{l}\text { Surface } \\
\text { condition }\end{array}$ & - & shiny & not shiny & shiny & shiny & shiny \\
\hline Diameter & $\mathrm{mm}$ & 8 & 8 & - & $6-8$ & $6-8$ \\
\hline Length & $\mathrm{mm}$ & 12 & 12 & $<50$ & $3.15-40$ & $3.15-40$ \\
\hline Density & $\mathrm{kg} / \mathrm{l}$ & 0.3 & 0.27 & $1-1.4$ & $\geq 0.6$ & $\geq 0.6$ \\
\hline Ash content & $\%$ & 6.14 & 6.14 & $<1.5$ & $\leq 0.7$ & $\leq 3.0$ \\
\hline $\begin{array}{l}\text { Moisture } \\
\text { content }\end{array}$ & $\%$ & 14.2 & 14.2 & $<12$ & $\leq 10$ & $\leq 10$ \\
\hline $\begin{array}{l}\text { Calorific } \\
\text { value }\end{array}$ & $\mathrm{kJ} / \mathrm{kg}$ & 16650 & 16640 & $17500-19500$ & $16500-19000$ & $1650-19000$ \\
\hline
\end{tabular}

*sources : http://www.enplus-pellets.de

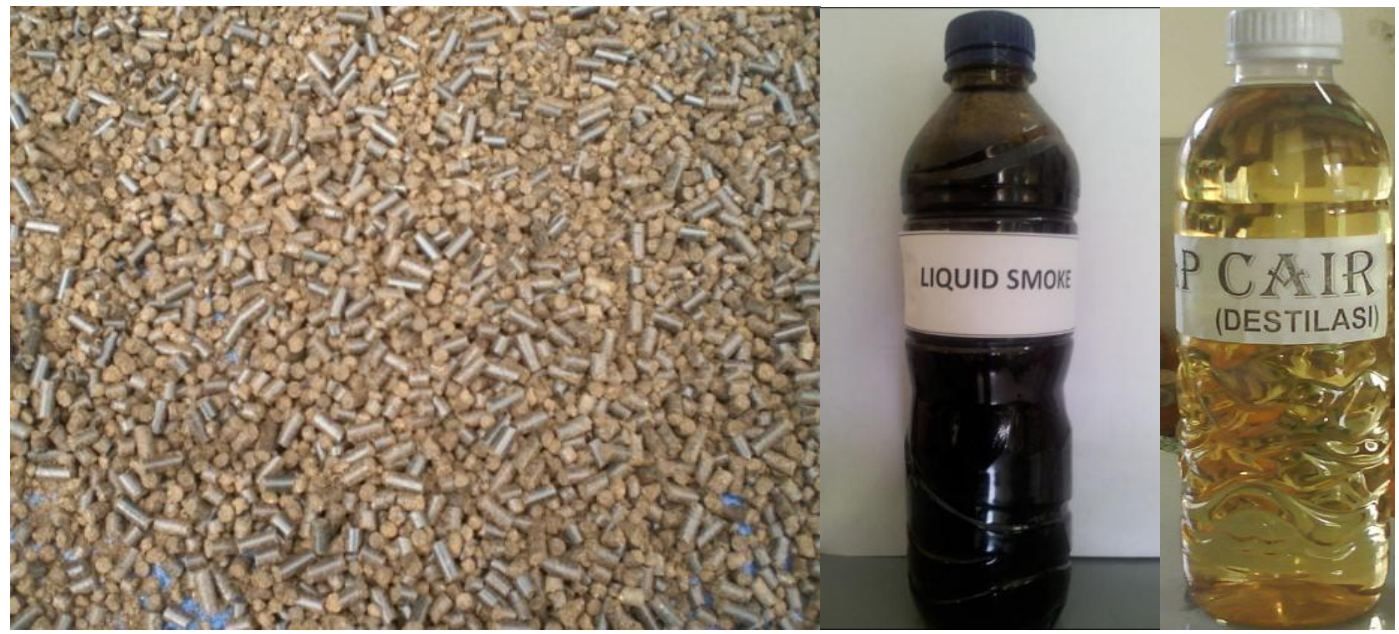

(a)

(b)

(c)

Figure 4. Coco peat pellet (a), crude liquid smoke (b), and refined liquid smoke (c) 
the quality of biomass pellet is mostly referred to wood pellets specification. Wood pellet specification itself can vary greatly and should conform to one of the specifications e.g: 1) DIN 51731 Standard, 2) ENplus A1, and 3) European Norms (EN-B).

Based on the coco peat pellet experiment, Formula I exhibited better quality than Formula II in terms of texture, surface and calorific value. According to standards from DIN 51731, ENplus A1, and EN-B, biomass pellet should have strong texture, shiny surface with minimum caloric value of $16.500-19.000 \mathrm{~kJ} / \mathrm{kg}$. Coco peat pellet Formula I showed solid and strong texture as well as darker color. The formulas have calorific values of $16650 \mathrm{~kJ} / \mathrm{kg}$ and 16640 $\mathrm{kJ} / \mathrm{kg}$ respectively. They have met calorific value parameters required by all standards mentioned above and stated in Table 1 . The calorific value is the useful energy contained in a kilogram of fuel. This value is affected by the amount of non-combustible material (ash) and the moisture content of the pellet.

Pellets produced from this experiment have an ash content of $6.14 \%$ which is much higher than all existing standards. This was due to the raw material (coco peat) which is more fragile when compared to the wood pellet or other biomass resources. To improve this condition, it would be better if coco peat is mixed with other biomass materials which do not easily makes the pellets fragile. Since the mixture of coco peat was difficult to be pelletized, it was then mixed with waste cooking oil to improve rheological properties of pellet when pelletizing. The results shows that pellet with $85 \%$ coco peat and $10 \%$ waste cooking oil exhibited stronger texture and shiny surface rather than that with $90 \%$ coco peat and 5\% waste cooking oil which have no shiny surface and are likely to crumble and produce fine particles that pass through an 1/8 inch screen.

Ash represents the non-combustible content of the pellet. Higher ash content reduces the calorific value of the pellet and requires the appliance to be cleaned more frequently. The goal of this experiment is to produce pellets that are free flowing, essentially dust free, and relatively compact for storage. The desired texture should have shiny surface and fines no more than $0.5 \%$ by weight. The higher ash content of coco peat pellet produced in this experiment is because of the nature of coco peat which is very brittle or fragile. According to PelHeat (2010) good quality pellet is one which has very low ash content, for example $0.3 \%$.

The density of pellet based on the DIN 51731 standard for wood pellets is $1-1.4 \mathrm{~kg} / \mathrm{l}$. The density of pellet produced from this experiment was $0.27-0.3 \mathrm{~kg} / \mathrm{l}$ which was lower than the standard required. As recommended by pellet manufacturing industries, usual sizes of pellet are $6 \mathrm{~mm}, 8 \mathrm{~mm}, \mathrm{~L} \leq 5 \mathrm{D}$ ( $\mathrm{L}$ and $\mathrm{D}$ mean length and diameter respectively). To provide a predictable flow of fuel into the burner, the recommended length of a pellet should be greater than $5 \mathrm{~mm}$ and less than 5 times than the diameter (DIN 51731). The length and diameter of the pellet produced were $12 \mathrm{~mm}$ and $6 \mathrm{~mm}$, respectively and it means that all dimensions meet the standard required. Density is a crucial indicator that the pellets are produced under the correct pressure. Though they have density lower than the European Standard, it can still be used as fuel pellet.

Moisture content is one of the important parameters that can influence the production of syngas. The lesser the moisture content, the better the quality of pellet becomes and the less smoke is produced when ignited at the first burning of coco peat pellet. In this experiment the moisture content obtained was $14.2 \%$. Moisture affects the calorific value of the pellet. Low moisture content guarantees constant and predictable combustion efficiency. Higher moisture contents can result in pellet breakdown. Quality pellets characteristic should have moisture content below $12 \%$ and be mechanically strong with a good density.

In this experiment the pellet produced was tested by placing them in a glass of water. It can be seen that the pellet sinks to the bottom as shown on Figure 5, and this corresponds to the Koefman (2007). Koefmen (2007) stated that the simplest way to test pellet quality is to place a pellet in a glass of water. If the pellet sinks to 


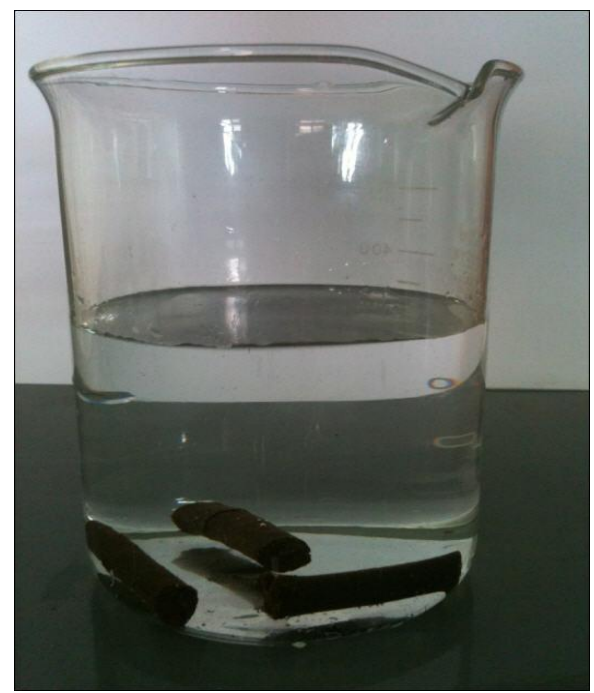

Figure 5. Qualitative pellet testing

the bottom the pellet has a high density, and was formed under sufficient pressure. However if the pellet floats show that the pellet quality is poor as it has a low density, lower mechanical durability and is more likely to crumble and produce fines.

This study also included research on coco peat briquette production using jack press (without pelletizing) and to be compared with the coco peat pellets (Figure 6). When the briquette was used for gasification the syngas was not generated. The experimental results obtained from briquettes were not satisfactory, as it was very difficult for briquettes to be gasified than the pellet form. Below is the picture of coco peat briquettes with diameter greater than the length of pellets but it is more fragile than pellets.

\section{Coco Peat Pellet Gasification and Emission Test}

Evaluation of coco peat on the gasifier stove for several experiments is shown in Table 2. In this experiment, the volumetric flow of syngas was measured in terms of the duration of using syngas both for drying coconut and boiling of water. Gas can be generated within a minute after igniting the fuel and it was observed that for the first ten (10) minutes the stove could not operate satisfactorily since some smoke appeared due to high moisture content of pellet. Some

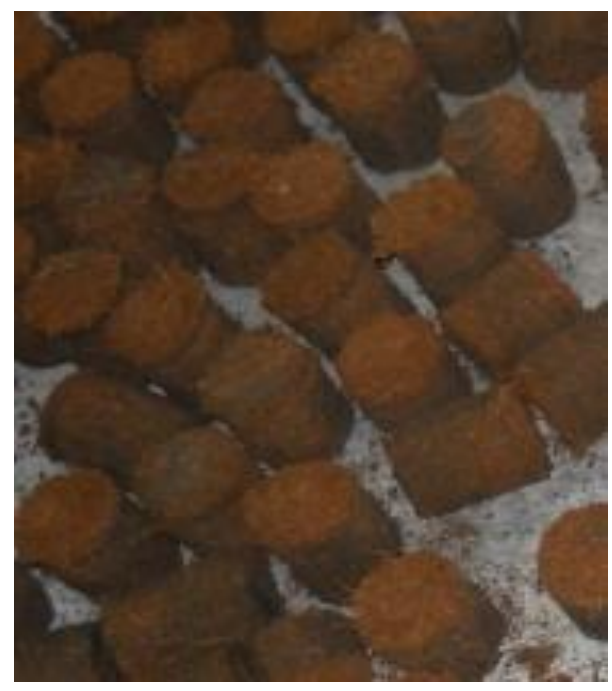

Figure 6. Coco peat briquette

smoke occasionally emerged from the air inlet passage during steady stove operation. Combustion was very clean due to the perfect burning of the volatiles produced from the pellets. Occasionally some smoke was seen to escape from the stove. Higher moisture content of coco peat pellet could be the reason for lower efficiency observed in case of generation of the smoke. Besides syngas, liquid smoke or cocopeat vinegar was also generated and the volume of coco peat vinegar was presented in Table 2.

Performance evaluation of the gasification of coco peat pellets exhibited different results and it was correlated with the amount of feed to the stove. As seen from Table $2,5 \mathrm{~kg}$ feed showed the longer durations of 3.5 hours (Formula I) and 3.25 hour (Formula II). This means that gasification time were not significant between the amount of coco peat pellet of the half volume of gasifier $(5 \mathrm{~kg})$ and the three quarters of gasifier $(10 \mathrm{~kg})$. This is due to less distribution of biomass pellets in the gasifier that causes accumulation of pellets in the gasifier. Also this accumulation would cause cross sectional area for gasification of coco peat pellets become lower.

The volume of coco peat vinegar produced was also similar with the gas produced where there was no significant difference. On this condition, syngas produced was dominant and 
Table 2. Gasification performance using coco peat pellet

\begin{tabular}{|c|c|c|c|}
\hline Formula & Feed (kg) & $\begin{array}{c}\text { Syngas production time } \\
\text { (hour) }\end{array}$ & $\begin{array}{c}\text { Volume of liquid } \\
\text { smoke (mL) }\end{array}$ \\
\hline Formula I & 2.5 & 1.5 & 500 \\
& 5 & 3.5 & 1350 \\
& 10 & 3.0 & 1350 \\
\hline \multirow{2}{*}{ Formula II } & 2.5 & 1.5 & 400 \\
& 5 & 3.25 & 1200 \\
& 10 & 3.0 & 1200 \\
\hline
\end{tabular}

Table 3. Emission test analysis of coco peat pellet gasification

\begin{tabular}{|l|l|c|c|}
\hline \multicolumn{2}{|c|}{ Sample } & Test result & $\begin{array}{c}\text { Air Quality Standards on } \\
\text { Atationary Source Emissions* }\end{array}$ \\
\hline \multicolumn{1}{|c|}{ Parameter } & \multicolumn{1}{|c|}{ Unit } & & \\
\cline { 1 - 2 } $\mathrm{NH}_{3}$ & $\%$ & $<0.007$ & 0.5 \\
$\mathrm{Cl}_{2}$ & $\mathrm{mg} / 100 \mathrm{~g}$ & $<0.03$ & 10 \\
$\mathrm{HCl}$ & $\mathrm{mg} / 100 \mathrm{~g}$ & 0.0001 & 5 \\
$\mathrm{HF}$ & $\mathrm{mg} / 100 \mathrm{~g}$ & $<0.29$ & 10 \\
$\mathrm{NO}_{2}$ & $\mathrm{mg} / \mathrm{m}^{3}$ & $<0.004$ & 1000 \\
$\mathrm{Particle}^{2}$ & $\mathrm{mg} / \mathrm{kg}$ & 0.002 & 350 \\
$\mathrm{SO}_{2}$ & $\mathrm{mg} / \mathrm{kg}$ & $<0.02$ & 800 \\
$\mathrm{H}_{2} \mathrm{~S}$ & $\mathrm{mg} / \mathrm{kg}$ & $<0.002$ & 35 \\
$\mathrm{CO}^{2}$ & $\mathrm{mg} / \mathrm{kg}$ & $<0.0001$ & \\
$\mathrm{CO}_{2}$ & $\mathrm{mg} / \mathrm{kg}$ & $<0.0001$ & \\
\hline
\end{tabular}

*Based on Decree of the Minister of Environment on Standards of Quality Stationary Source Emissions No: KEP-13/MENLH/3/1995 dated March $7^{\text {th }}, 1995$ 
gasification process was running perfectly. This shows that chemical processes which run or react in gasifier meet three step gasification processes namely pyrolysis, partial oxidation, and steam reforming (Jansen, 2011).

\section{Emission Test}

All experiments were carried out under standard atmospheric pressure with air temperature of $30^{\circ} \mathrm{C}$. Table 3 shows the components of the gas mixtures which came from the stoves. It can be seen that the content of nitrogen was below the standard required. Low nitrogen content indicates that the pellets were made from pure coco peat. High levels of nitrogen in the flue gas emissions can give rise to corrosion. It can also be seen from this table that the sulfur content $\left(\mathrm{H}_{2} \mathrm{~S}\right)$ e.g. $<0.002$ was below of limit required $(35 \mathrm{mg} / \mathrm{kg})$. According to the DIN 51731 standard, low sulfur content indicates that the pellets were made from pure coco peat. High levels of sulfur in the flue gas emissions can give rise to corrosion.

\section{Conclusions}

This study has revealed that coco peat as biomass waste, which was difficult to dispose, can now be utilized as solid fuel for stoves to produce syngas. The composition of pellet with $85 \%$ coco peat waste, $5 \%$ tapioca starch (binding agent) and $10 \%$ waste cooking oil resulted in the best quality pellets with stronger texture and shiny surface. The experimental gasification using updraft gasifier exhibited better result when half of the volume of gasifier was filled with $5 \mathrm{~kg}$ pellet and the syngas produced can be used for 3.5 hours drying and boiling. The emission test results of pellet gasification showed that emission from gasification of coco peat pellet produced in this experiment meet the requirement of Air Quality Standards stipulated by Decree of the Minister of Environment on Standards.

\section{Acknowledgement}

We would like to express our sincere gratitude and appreciation to Ms. Nora (China Agricultural University-CAU Republic of China) for discussion regarding gasification stove during the experiments.

\section{References}

Abdullah, K. 2009. Sustainable parameters in introducing renewable energy Technology. ISESCO Science and Technology Vision 5(8): 7-10.

Abdullah, K. 2007. Renewable Energy in Supporting Agricultural Rural Area Development, IPB Press, ISBN, 978-979493150-9.

Alamsyah, R., Junaidi, L., Supriatna, Kosasih, and Suhendi, A.2011. Low Emission Biomass Pellet Production for substitution of Oil Fuel. Internal Report, Center for Agro-based Industry (CABI), Bogor.

Allorerung, D., dan A. Lay. 1998. The Possibilities of Integrated Coconut Processing Unit Development for Rural Area Scale. The $4^{\text {th }}$ Proceeding on National Coconut Conference.: 327-340.

Asian and Pacific Coconut Community (APCC). 2012. Indonesia's Monthly Exports, The Community. 42(6): 31-32

Ariati, R. 2007. Kebijakan Nasional Pengembangan Biofuel. Makalah disampaikan dalam Workshop Desain Pabrik Biodiesel Skala Mini, Serpong 1315 Nopember 2007. BRDST (BPPT), MerRistek, DJLPE (ESDM), dan PT. Astra Agro Lestari Tbk.

Azimov, U., Tomita, E., Kawahara, N., Dol, S.S,. 2012. Combustion Characteristics of Syngas and Natural Gas in Micro-pilot Ignited Dual-fuel Engine. World Academy of Science, Engineering and Technology 72: 1769-1776.

Belonio, A. 2012. Cocopeat Pellet Gas Stove. http://biomass-events.com/promopellet_characteristics.html (accessed November 29, 2012).

Carraretto, C., A. Macor, A. Mirandola, A. Stopatto and S. Tonon. 2004. Biodiesel as alternative fuel: Experimental analysis and energetic evaluations. In Energi 29:2195 2211. 
DIN 51731.2012.Testing of solid fuels Compressed untreated wood Requirements and testing, http://www.techstreet.com/standards/din/ (accessed November 29, 2012).

Directorate General of Estate Crops.2011. Coconut Production by Province of Smalholders, State Owned and Private Enterprite Estate,2005 - 2011, Directorate General of Estate Crops, Ministry of Agriculture of Indonesia.

ENplus.2011. Find ENplus certified pellet producers and traders, http://www.enpluspellets.de (accessed November 29, 2012).

Jansen, T.2011.Gasification of Woody Biomass. University of Twente, Netherlands.

Kofman, P. D. 2007. Simple ways to check wood pellet quality. Processing / Products No. 11 This article was reproduced with permission from Bioenergy News, SEI REIO, Winter COFORD , 2006-2007: 89.

Kristijono, A. 2010. Utilization of Peat As Plant Growth Media (Seed Self-Sufficient) to Support Critical Land Rehabilitation, Final Report, Agency for the Assessment and Application of Technology.

Mahmud, Z and Ferry, Y. 2005. The prospect of coconut by product application, Perspektif 4(2): 55-63.

Ministerial Decree of the Minister of Environment on Standards of Quality Stationary Source Emissions No: KEP13/MENLH/3/1995 dated March $7^{\text {th }}, 1995$.
Mani, S., L. G. Tabil, and S. Sokhansanj. 2003. An overview of compaction of biomass grinds. Powder Handling and Processing 15(3): 160-168.

Nielsen N.P., Gardner D.J., Poulsen T. and, Felby C. $2009 . \quad$ Importance of temperature, moisture content, and species for the conversion process of wood residues into fuel pellets. Wood and Fiber Science 41(4): 414-425.

PelHeat.2010. Biomass Pellet Production Guide, http://www.PelHeat.com (accessed November 29, 2012).

Perry, R. H., and D. W. Green. 1999. Perry's Chemical Engineers' Handbook. New York: McGraw Hill Inc.

Pfost, H. B., and Young, L.R.. 1974. Effect of colloidal binder and other factors on pelleting. Feedstuffs 45(49): 22.

Robinson, R. 1984. Manufacture of Animal Feed. Turrent-Wheatland Ltd. Herts, England.

Romulo, N. A., Jr.2012. Market access for coconut products. Cocoinfo International 19(2).

Romulo, N. A., Jr. 2009. The Situation and Prospects for The Utilization Of Coconut Wood In Asia And The Pacific. Working Paper No. Apfsos Ii/Wp/2009/15, Food and Agriculture Organization of The United Nations. Regional Office For Asia And The Pacific, Bangkok.

Salim, A.D.2000. Energy Reserved Energy Demands, and Future Technology. Workshop on Environmentally Friendly Technology for the Future. Jakarta. 